\title{
Comparative Analysis of the Structural Variety of Complex Syntactic Units in the English and Azerbaijani Languages
}

\author{
Dunyamin Yunusov ${ }^{1} \&$ Vahid Arabov $^{1}$ \\ ${ }^{1}$ Azerbaijan University of Languages, Baku, Azerbaijan \\ Correspondences: Dunyamin Yunusov, Vahid Arabov, Azerbaijan University of Languages, Baku, Azerbaijan. \\ E-mail: dunyaminyunusov@adu.edu.az
}

Received: November 27, 2014

Accepted: December 22, 2014 Online Published: January 27, 2015

doi:10.5539/ijel.v5n1p184

URL: http://dx.doi.org/10.5539/ijel.v5n1p184

\begin{abstract}
The article has been written on the basis of comparative-typological method in the study of the languages (the English and Azerbaijani languages) belonging to different language systems (English belonging to analytical type of languages, Azerbaijani to the synthetic type of languages). The main aim of the investigation is to find out similarities and distinctions between variant and invariant expressions of meaning in the both languages. We have aimed at studying this problem from the view of varieties in different language levels. The varieties of different levels are regulated by laws within the system of a language laws and comprise positional combinatory and distributional variants which belong to inner system laws and comprise positional combinatory and distributional variants which belong to structural varieties-within the system of the language.

In this research work on the problem of variants and invariants, problem of dichotomy of language-speech, the problems related to them, social and individual problems in the both languages, system and norm and other problems have undergone scientific investigation.

In the introduction of the article it is pointed out that the varieties (phonological mainly) have been investigated on the functional aspect in the both compared languages. Here the terms "variant" and "invariant" have found their linguistic interpretation. The coauthors of the article basing on the variant and invariant problems in the both English and Azerbaijani languages, have made attempts to throw light on the problem of variations in complex syntactic units in the compared languages.

Within the scope of the study of the investigated problem the coauthors have introduced discussions of the scholars dealing with the problem of variations, including variants and invariants in the both compared languages. Aimed at making experimental evidences the coauthors have introduced the tables, showing variations in the compared languages in which varieties of the vowel (i) in complex syntactic units in the both languages pronounced in different positions have been indicated (see tables 1, 2, 3). Tables have been taken from (Yunusov, 2005; 2007).

In the conclusion of the research work the authors have reflected the generalized consideration touched upon in the process of investigation.
\end{abstract}

Keywords: structural variety, complex syntactic units, variants, invariants

\section{Introduction}

The variants of different units may oppose only to their units, but not others. Varieties have been investigated either on the language functional plan /e.g. the role of variants in forming literary language), or on the system of phonetic and grammatical aspects. On this account the interpretation of varieties in different language levels, especially its structural, formal and semantic varieties, their interrelationship with one another and other problems expect their profound systematic solutions.

Under variant we understand two or more formal modifications without being related to certain changes of meaning. Variants may appear under the speaker's aim and object, under the situation of speech communication and under special language material etc.

Without going into details, we can say that each complex syntactic unit may take part in various variants in the complex sentence paradigms. The languages belonging to different language families (English and Azerbaijani) 
cover these variants and these variants appear depending upon the syntactic -structural and semantics of the verb-predicate properties (Stepanov, 1979).

However it is highly important to consider the complex syntactic unit from all these points of views. The problem of classifying subordinate clauses is one of the vexed questions of syntactic theory. Several systems have been tested at various times, and practically each of them has seemed to possess some drawbacks. Some of the classifications so far proposed, have been inconsistent, that is to say, they do not base on any firm principle of division which equally can be applied to all clauses to be considered.

\section{Scope of the Study}

Investigating the varieties in different language levels, the majority of scholars show that the varieties of different levels are regulated by the laws of inner system and comprise positional, combinatory and distributional variants which belong to inner structural varieties. Investigating the problem of variants and invariants should help the problem of dichotomy of language - speech, the problems related with it, social and individual problems in languages, system and norm and other problems. It is clear that the unity of different points determine the place of units in the related systems. The description of those non-differential relations puts forward the system of variants. The system of variants doesn't have less importance than the system of invariants in the interpretation of the linguistic phenomena.

Units exist only in their variants. It should be mentioned here that the system of variants is restricted with the language norms. The units existing in their variants should oppose to one another in this frame (Stepanov, 1979).

Undoubtedly, intonation variations of the languages may help the scholars to solve this problem. As to Stepanov (1979), variation in itself is one of the main problems of the language. It is not possible to ignore the thought of Q. P. Torsuev, saying that "constancy and variation are one of the most important features of language structure" (Torsuev, 1977).

A. Martine points out that "in the expression plan variant and invariant confrontation has been determined by the scholars of Prague linguistic school, and have been named as the invariant and as a phoneme" (Martine, 1970).

As to Wallace Chafe the representatives of the Prague linguistic school, glossematics and American descriptives tried to affirm taxonomic method in the science on linguistics (Chafe, 1975)

L. Bloomfield who headed American descriptive linguistics repeatedly stressing the importance of meaning, stated that it was too early to study it (Bloomfield, 1968).

N. Chomskyi mentioned that one of the defective points of the structuralists was the fact that they ignored the "phonetic bias" (Chomsky, 1962).

This problem has been studied in the Azerbaijani linguistics as well. Speaking on the role of tone in the pronunciation of the syntactic units within the complex sentences majority of these linguists shared the view on the determination of tones in the complex sentences. As to them within the complex sentences, the components of the syntactic units, the principal and the subordinate clauses have two tones: subordinating and subordinated tones depending upon the type of sentences.

In the complex sentences the first coming sentence is pronounced with rising tone, while the second one is pronounced with descending tone (Abdullayev, 1999; Abdullayev, 1974).

Under variant we understand two or more formal modifications without being subjected to certain changes of meaning. Variants may appear depending on the speaker's aim and object, under the situation of speech communication and under special language material etc. The considered material makes it possible for us to say that each complex syntactic unit may take part in various variants in the complex sentence paradigms (Yunusov, 2005 ; 2008).

Usually the classification of complex syntactic units is based on the type of the subordinate clause, its function and meaning, and also on the conjunctions and connecting words. This method, though being highly important for the understanding and analysis of various types of subordinate clauses, is not satisfactory, in that the structure of the complex sentence as a whole and the structure of the main clause as its basic element is not taken into consideration. Besides, this classification doesn't take into consideration the fact that subordination as a way of connecting two clauses may vary from the view of a close relation to a very loose connection, with many gradations in between; then, the relative importance of the main and the subordinate clause may also be different, sometimes it is the subordinate clause which contains the main idea, the role of the main clause being tended to expressing modal shades of meaning -doubt, sureness and so on. 


\section{Research Methodology}

We have used in this article comparative typological method in the investigation of the problem of variants and invariants, problem of dichotomy of language-speech, the problem of system and norm in the structural varieties of complex syntactic units in the English and Azerbaijani languages.

\section{Variation of the Complex Syntactic Units}

We base on the first postulation and continue our investigation. We suppose that separately each of these complex syntactic units having different realization forms gets only one invariant form. The mentioned theoretical problem should be explained like this.

If we take one of the types of complex syntactic units in any compared languages and show the realization of their phonetic variants in one type, this type will keep its stability in different spoken situations, so these types of complex syntactic units, let's suppose subordinate clauses of object, differ from the types of attributive subordinate clauses both by their formal-structural and semantical points and oppose to them. Formally, though the object subordinate clauses appear in some variants, semantically, they perform the function of an object to the predicate - verb of the principal clause or it may also refer to a non-finite form of the verb, to an adjective, or to a word belonging to the part of speech expressing state. But the meaning of the attributive subordinate clauses is to qualify the antecedent. Unlike the object subordinate clauses, the attributive subordinate clauses serve as an attribute to a noun (pronoun) in the principal clause.

As the meaning of object differs from the meaning of attribute semantically, the variants of object will differ from the corresponding variants of attribute formally as well.

In other words these two complex syntactic units like two abstract models oppose to each other in the syntactic level of the language. They keep their independence like object and attributive subordinate clauses in the language system. Accordingly each of these complex syntactic units has its own possible variants. Those possible variants of the complex syntactic units have got their own realization forms in speech. Those realization forms are related with different concrete types etc.

Summing up all above mentioned we may come to the conclusion that the object and attributive subordinate clauses like different complex syntactic units oppose to each other in language system and they are opposed like two communicative models. If the predicate - verb of the principal clause of object subordinate clauses is expressed by the verbs of "saying", this complex syntactic unit has got minimum ten realization forms. These realization forms separately have got a lot of chances of usage in different situations. The same realization forms can be observed in the attributive subordinate clauses as well. What kind of features make these variants appear and how these related to each other by their intonation - structural points are coordinated? It should be mentioned that the individual features of realization of each complex syntactic unit is less important. On this account study of "individuals" is of great importance in studying "common" points. If the "individuals" differ from each other, they always reveal the properties of "common" and "individual" problems. In other words, if the "individuals" don't have the relations tending to "commons", they can't exist in the language. "Commons" can only exist by means of "individuals" going through the "special" points. Each "common" is considered to be an "individual". Each "common" approximately comprises all the "individual" objects. Each "individual", though incomplete, includes the "common" and so on and so forth. If we interprete above mentioned philosophical conception concerning to complex syntactic units, we can show that the object subordinate clauses as "common", possess their variants as "special" and their patterns as "individual".

This interpretation has got a great importance in investigating complex syntactic units from the point of constancy and variety in languages of different systems.

But what results should be gained by the contrastive structure studies of the variety of complex syntactic units in the non-kindred English and Azerbaijani languages? The experimental analysis prove that it is possible to find out a lot of morphs and allomorphs between these compared languages.

Comparative analysis of the melodic structure variety of complex syntactic units in the English and Azerbaijani languages proves that under different factors, i.e., the syntactic structure, the position of the components of complex syntactic units, the semantic side of each component and the expanding of components by the addition of lexical elements, the melodic structure variety of different complex syntactic units in the compared languages differ from one another. While investigating the English and Azerbaijani complex syntactic units, we have found out that the syndetic elements, i.e., the conjunctions, conjunctive pronouns, conjunctive adverbs, relative pronouns and relative adverbs also affect on the melodic structure variety of complex syntactic units in languages of different systems. Under the use of those above mentioned syndetic elements the syntagmatic 
division of complex syntactic units takes place not only between the juncture of the components of complex syntactic units but also within syntagms or clauses (components). They are called either within syntagmdivision or within (inner) component (clause) division. The results of experimental-phonetic investigation show that in the English language the frequent usage of those syndetic elements is shown in the usage of the following conjunctions: "that", "what", "how", "who", "why", "where", "if", "whether", "when", "which" and "whose".

Comparative analysis of the melodic structure variety in the languages of different systems shows that the syntagmatic division takes place after the verbs expressing "wish", "desire" offered by L.L.Iofik (Iofik, 1953). The analysis of the melodic structure variety of complex syntactic units in the English and Azerbaijani languages shows that the components "he knew" in the complex syntactic unit "He knew that Carrie listened to him pleasurably" and "Cahan bilirdi ki" in the sentence "Cahan bilirdi ki, çatini bela sözlar yayllıncadır" differ from each other by their melodic structure variety. It should be mentioned that they differ from each other formerly. If in the English complex syntactic unit, the conjunction "that" is used with the subordinate clause, in the Azerbaijani language the conjunction "ki" joins the principal clause. And by virtue of it the structure of those complex syntactic units undergoes the melodic variety. If the main tone of the component "he knew" is changed between $230 \mathrm{hz}$ and $125 \mathrm{hz}$, the main tone of the component "Cahan bilirdi ki" is changed between $250 \mathrm{hz}$ and 130hz. The width of diapazone in the English sentence is $115 \mathrm{hz}$ but in Azerbaijani it equals $140 \mathrm{hz}$. As it is seen in the Azerbaijani language, the width of diapazone is larger than the width of diapazone in the English language It should be mentioned that though the conjunctions "that", "ki" can't make up a communicative centre, generally they can occupy the melodic peak in different complex syntactic units in the languages of different systems.

Comparative analysis of the structure of complex syntactic units "The man looked at him and saw that he was deathly pale", "He saw clearly that this was her idea", "Nəhayət anladım ki, öz üzərimə gücümdən çox-çox böyük yük götürürəm", "Sonra bildim ki, bunların harəsi on manatliqdır" show that the expanding of each components with different lexical elements influences not only on the melodic structure variety of complex syntactic units in the compared languages but also it changes the syntagmatic division in each of those above-mentioned subordinate clauses. It should be noted that here grammatical and semantical relations of the components of complex syntactic units, the modal-emotional colouring of the situation, the structural point and the position of the components within the complex syntactic units should be taken into account as well.

Comparative analysis of the melodic structure variety of complex syntactic units shows that the syndetical types "He recollected with satisfaction that he had bought that house over Jame's head", "You know very well that that has nothing to do with it", "You know very well that I couldn't tell anyone the reason", "Nahayat anladim ki, öz üzarimə gücümdən çox-çox böyük yük götürürəm", "İndi başa düşürəm ki, cinayət eləmişəm” and "Sonra bildim ki, bunlarm harasi on manatliqdir", the adverbial word groups in each of them accordingly "with satisfaction", "very well", "nəhayat", "indi" and "sonra" increase the semantic meaning of the verb-predicate in the principal clauses. By virtue of the use of those adverbial word groups in the principal clauses of the complex syntactic units, the melodic structure variety of the principal clauses of these complex syntactic units is pronounced with the rising tone. Unlike the Azerbaijani complex syntactic units, the English complex syntactic unit "You know very well that that has nothing to do with it" acquires one more distinguished feature. That's the adverbial word group "very well" differs from other adverbial word groups such as "then", "at last", "now" by its character. The adverbial word group "very well" is closely connected with the verb-predicate "know" expressing the meaning of mental activity.

The experimental analysis of phoneme (i) in the complex syntactic unit "He was just a bit stupid you know not very bright" and the same phoneme in the Azerbaijani language. "Nəriman düz deyir bu kağız şübhali kağızdır", and table 3, illustrating the dynamic varieties of the complex syntactic unit "I'll tell you I'll do" may show us differentiations on the progradient and terminal syntagms on the phoneme varieties (see tables)

Table 1. Varieties of the vowel (1) in complex syntactic unit "He was just a bit stupid you know not very bright" in different positions

\begin{tabular}{llll}
\hline Vowels & $1_{1}$ & $1_{2}$ & $1_{3}$ \\
\hline I announcer & 1,7 & 1,2 & 0,7 \\
II announcer & 1,8 & 1,7 & 0,5 \\
\hline
\end{tabular}


Table 2. Varieties of the vowel (1) in complex syntactic unit "Noriman düz deyir bu kağız şübhəli kağızdır" in different positions

\begin{tabular}{llll}
\hline Vowels & $1_{1}$ & $1_{2}$ & $1_{3}$ \\
\hline I announcer & 2,1 & 1,4 & 0,9 \\
II announcer & 2 & 1,1 & 0,8 \\
\hline
\end{tabular}

Table 3. Dynamic varieties of the complex syntactic unit "I'll tell you that I'll do"

\begin{tabular}{|c|c|c|c|c|c|c|c|}
\hline Announcers & $\begin{array}{l}\text { Vowels } \\
\text { syntagms }\end{array}$ & a1 & $\mathrm{e}$ & $\mathrm{u}:$ & 5 & a1 & $\mathrm{u}$ : \\
\hline \multirow[t]{2}{*}{ I announcer } & progradient & 0,8 & 1,2 & 1,2 & & & \\
\hline & terminal & & & & 2 & 1,3 & 0,5 \\
\hline \multirow[t]{2}{*}{ II announcer } & progradient & 1,5 & 1,7 & 1,6 & & & \\
\hline & terminal & & & & 0,4 & 1 & 0,2 \\
\hline
\end{tabular}

Comparative analysis of the melodic structure variety of complex syntactic units in the English and Azerbaijani languages proves that investigating any structural type of syntactic unit helps to widen investigation of the problem of constancy and variety in general linguistics. The main and positive aspect of this guide is in its experimental-phonetic study. Comparative analysis shows that though the complex syntactic units in the English and Azerbaijani languages gain a lot of forms in their melodic varieties, they never reach the level of invariant point. Though these variants become different apparents, they are only determined by their constituent parts, but not others. Those variants are united with those common points which are the same for all, that's invariant. But at the same time according to the melodic structure variety these different apparent forms are grouped by variants. These variants have some common and different characters (Yunusov, 2007).

\section{Conclusion}

Scientific investigation of comparative analysis of the structural variety of complex syntactic units in the English and Azerbaijani languages makes it possible for us to come to the following conclusions:

1. discussions of scholars both in English and Azerbaijani linguistics grounded on different language systems show that approach to the problem in the both languages are different;

2. each of the complex syntactic units in the phonetic plan opposes to the other intonation counter part. The appearance of any variant mostly depends upon the syntactic-semantic and syntagmatic structure of the complex syntactic units in languages of different systems;

3. experimental analysis of the dynamic varieties of the complex syntactic unit "I'll tell you that I'll do" in the English example in the pronunciation of English diphthongs and monophthongs (ai, e, u: 5, a9, u) by two annoucers shows that they are different as to progradient and terminal syntagms;

4. different points are observed in asyndetic and syndetic structural types of complex syntactic units depending upon the peak of communicative center and the whole synactic units as well;

5. comparative analysis of the melodic structure variety of complex syntactic units in the English and Azerbaijani languages shows that in Azerbaijani syntactic units, the width of diapazone happens to be in progradiyent syntagms much more than in English; the introduced tables 1,2, may serve to prove the justification of the mentioned by us the thesis;

6. the melodic structure analysis of the complex syntactic units in the English and Azerbaijani languages proves that not all the syntactic units gain the syntagmatic division between the juncture of the components in the compared languages;

7. comparative analysis of the melodic structure variety of complex syntactic units in the English and Azerbaijani languages proves that if the verb-predicate of the principal clause of complex syntactic units in the compared languages is expressed by the verbs of "mental activity", the melodic structure of the first components in the compared languages is characterized by the rising tone. But if it is expressed by the verbs of "speech" we can't possibly observe this scene;

8. unlike the structural type of asyndetic complex syntactic units, in the structural type of syndetic complex syntactic units the conjunction "that" carries out much more phonetic freight. So the conjunctions can't be considered simply the formal grammatical means between the components of the complex syntactic units in the 
compared languages. Removing the conjunctions out of the structural type of syndetic complex syntactic units sometimes puts the meaning into confusion.

\section{References}

Abdullayev, A. Z. (1974). Complex sentences in Modern Azerbaijani. Baku, Maarif.

Abdullayev, K. M. (1999). Theoretical problems of the syntax of the Azerbaijani language. Baku, Maarif.

Bloomfield, L. (1968). Language, Russian translation. Moscow.

Chafe, L. W. (1975). Meaning and structure of language. Moscow.

Chomsky, N. (1962). Syntactical structure. New in linguistics. Moscow.

Grammar of the Azerbaijani language. (1959). Baku, Academy of Sciences.

Hajiyeva, F. I. (1980). Ф.И. Variants of interrogative intonational contours in German and Azerbaijani. $\mathrm{PhD}$ dissertation, Baku.

Iofik, L. L. (1953). Some features of complex sentences in Modern English. LSU, 36.

Martine, A.(1970). La linguistique Synchronique (3rd ed.). London

Stepanov, G. B. (1979). Problem of variety of language. Moscow.

Torsuev, G. P. (1977). Constancy and variety in phonetic system. Moscow.

Yunusov, D. N. (1986). About some characteristic features of sentence intonation. Language structure and its modern methods of analysis, Baku.

Yunusov, D. N. (1991). Some issues of the phonetic structure of the Azerbaijani languages. ANSA Linguistics Institute. Baku, Science.

Yunusov, D. N. (2005). The variety of complete syntactic units in different systematic languages. Mutarjim.

Yunusov, D. N. (2006). A Guide to English Grammar. Baku: Mutarjim

Yunusov, D. N. (2007). Constancy and variety of complex syntactic units in languages of different systems. Istanbul.

Yunusov, D. N. (2008). Constancy and variety of complex syntactic units in languages of different systems. Bak1: E.L.

\section{Copyrights}

Copyright for this article is retained by the author(s), with first publication rights granted to the journal.

This is an open-access article distributed under the terms and conditions of the Creative Commons Attribution license (http://creativecommons.org/licenses/by/3.0/). 